\title{
Mathematical Modeling on Unbalanced Transportation problem for Solid Waste Management for the Reduction of Cost: Case of Jimma Town, South West Ethiopia
}

\author{
Yilekal Yewulu Tadesse \\ Department of Mathematics \\ Ethiopian Institute of Textile and Fashion Technology \\ Bahir Dar University, Ethiopia
}

\begin{abstract}
Municipal Solid Waste management services in Jimma city starts with collection by vehicles with a loading capacity of eight cubic meters and 52 metallic containers for waste storage and next stage is transportation to the existing dumping sites and disposal. However this collected waste did not transport to the dump early due to lacke of budget. This study have a great importance to reduces cost of transportation for solid waste. The required data for this study were collected from various research articles conducted and from Jimma town kebeles. Unbalanced transportation Problem is used to obtain the basic optimal feasible solution. The result of the study answers the question that, which kebele solid waste transported to which disposal site?
\end{abstract}

Key Words: Operation research, Modified Distribution, Transportation Problem, Solid Waste Management.

\section{INTRODUCTION}

Solid waste management is becoming a big concern for cities administration task in developing countries. This is mainly due to the magnitude of rapid urbanization and increasing population growth; which in turn has greatly accelerated municipal solid waste generation rate in the urban environment [1]. According to [9], every year developing nations spend nearly \$46 billion on managing their municipal solid waste. These investments could exceed $\$ 150$ billion per year by 2025 . Solid waste management (SWM) in Africa is often weak due to lack of appropriate planning, inadequate governance, poor technology, weak enforcement of existing legislation and lack of economic incentives [2]. In Ethiopia, rapid urbanization coupled with increased urban population in the last decade brought immense pressure on municipal services, mainly in the management of the ever increasing amounts of SW. Since the year 2001, most municipalities and city councils in developing countries and particularly in Ethiopia have become aware of the negative consequences of poor SWM [3].

Jimma, as one of rapid urbanizing town, is far from satisfying the infrastructure demand of its population and its solid waste management is poor. This in-adequate solid waste management in the town has resulted in the accumulation of waste on open lands, in drains and in the residential areas, causing a nuisance and foul-smelling pools, environmental pollution through leachate from piles (water and soil pollution) and burning of waste (air pollution), clogging of drains.

This situation is believed to result in poor environmental conditions, which in turn present a formidable threat to health. There is thus a need for improved waste management system of the town. Municipal Solid Waste management services in Jimma city starts with collection by vehicles with a loading capacity of eight cubic meters and 52 metallic containers for waste storage and next stage is transportation to the existing dumping sites and disposal. However this collected waste did not transport to the dump early due to lack of budget. [4] stated that to conduct the solid waste management properly Jimma town municipality should increase manpower, labor, and transport cost. According to the data from the municipality of the town, the administration allocates only $1 \%$ of the total budget for solid waste management [5].

Jimma municipality Green and Sanitation department runs this service with supplying only two dumping trucks, 52 storage containers and two regulated disposal sites located at Seka around Jimma airport and Marawa (at side of bada buna) which are 5and $7 \mathrm{kms}$ far away from the center of the town [6]. 
In the network optimization transportation problem is famous in operations research for its wide application in real life. This is a special kind in which goods are transported from a set of sources to a set of destinations subject to the supply and demand of the source and destination, respectively, such that the total cost of transportation is minimized.

This research aimed to minimize cost of transportation of solid waste management in case of Jimma town using un balanced Transportation problem.

\subsection{Statement of the problem}

Clean and health living conditions in cities and towns cannot be achieved without reliable and regular waste collection, Transportation and disposal systems. According to [7] in large number of Ethiopian urban areas, solid waste management services are either absent or insufficient. Jimma town is characterized by rapid population growth caused by natural increase and migration. According to 1994 national census report, the town had 88, 667 total populations whereas by 2007 national census reached 159, 009 with growth rate of 4.9\%/annum and the average households' family size is 4.38 [6]. Such rapid increase in population together with rapid development of the town has produced increasing volume of solid waste and in turn it induced greater infrastructural demand, institutional setup and community participation for its management.

According to the data from the municipality of the town, the administration allocates only $1 \%$ of the total budget for solid waste management [5]. Jimma town faced weak financial performance of solid waste management in this year (2018), the total budget allocated for Green and Sanitation department was about 175,230 ETB. But the required budget to carry out the service provision is about 275, 877 ETB and transportation take many of the budgets [6]. Due to shortage of budget the solid waste could not collet and transport to the dumb sites early this resulted causing environmental and health problems.

\subsection{Significance of the study}

* It reduces cost of transportation for solid waste.

* It will be a base line for the further study of solid waste management.

- It gives values for the control of municipal solid waste management.

\subsection{Objectives}

* To formulate a mathematical unbalanced transportation model for the given SWM management.

* To minimize the present transportation cost of wastes.

\section{METHODS AND MATERIALS}

\subsection{Study Area}

This study was conducted at Jimma town, Southwestern Ethiopia in 2007 censes it has a population of 159,009, with annual population growth rate of $4.9 \%$ and the total number of household units was 31,060 in the study area. The town had 21 kebeles, but recently after restructuring some kebeles were merged and by now the town has 13 administrative kebeles [6] . The daily, weekly, monthly and yearly solid waste generation rate of Jimma town was estimated to be $22.74,159.17,682.15$ and $8,299.47$ tons respectively and on averagely, a household generates $0.775 \mathrm{~kg} / \mathrm{HH} / \mathrm{day}$ [5].

\subsection{Data Collection}

The required data for this study were collected from various research articles conducted on the study area and the amount of waste produced from each generation nodes ( kebeles) and the distance between from the two dumping sites to each kebeles were collected. The data about the area and the capacity of the disposal site ware collected from Jimma town municipality. 
Table 1.Waste generated from generation nodes (kebeles) and distance from generation node to disposal site.

\begin{tabular}{|c|c|c|c|c|}
\hline \multirow[t]{2}{*}{ Sr. No. } & \multirow[t]{2}{*}{ Sources/kebeles } & \multicolumn{2}{|c|}{ Distance in $\mathbf{k m}$} & \multirow{2}{*}{$\begin{array}{c}\text { Supply (Ton) } \\
2018\end{array}$} \\
\hline & & Marawa & Koshi (Seka) & \\
\hline 1 & Bosa Kito & 8.1 & 5.1 & 263 \\
\hline 2 & Bosa Adis & 8.4 & 5.4 & 252 \\
\hline 3 & $\begin{array}{l}\text { Hermata } \\
\text { Mentina }\end{array}$ & 7.4 & 4.5 & 358 \\
\hline 4 & Jiren & 4 & 7 & 274 \\
\hline 5 & Mendera Kochi & 5.7 & 5.3 & 266 \\
\hline 6 & Bacho Bore & 4.2 & 6.3 & 361 \\
\hline 7 & Hermata Awetu & 7 & 4 & 301 \\
\hline 8 & Ginjo & 4.8 & 6.2 & 321 \\
\hline 9 & Ginjo Guderu & 5 & 6 & 191 \\
\hline 10 & Mentina & 8 & 5 & 223 \\
\hline 11 & $\begin{array}{l}\text { Hermata } \\
\text { Merkato }\end{array}$ & 7 & 4 & 402 \\
\hline 12 & Furestalie & 7.2 & 4.2 & 371 \\
\hline 13 & Effa Bula & 7.6 & 4.7 & 197 \\
\hline Car & city/ Demand & 1764 & 2396 & \\
\hline
\end{tabular}

\subsection{Methodology}

Transportation Problem (TP) is based on supply and demand of commodities transported from several sources to the different destinations. The sources from which we need to transport refer the supply while the destination where commodities arrive referred the demand. It has been seen that on many occasion, the decision problem can also be formatting as TP. In general we try to minimize total transportation cost for the commodities transporting from source to destination.

There are two types of transportation problems namely.

1. Balanced Transportation Problem: A transportation problem is said to be balanced transportation problem if total number of supply is same as total number of demand.

\section{Unbalanced Transportation Problem:}

A transportation problem is said to be unbalanced transportation problem if total number of supply is not same as total number of demand.

Thus far, the methods for determining an initial solution and an optimal solution have been demonstrated within the context of a balanced transportation model. Realistically, however, an unbalanced problem is a more likely occurrence.

Transporting solid waste is the current problem of jimma municipality but the capacity of the two dump site is more than the amount of waste produced from the source. The total capacity of the dump site are not balanced, hence unbalanced transportation problem is selected for solid waste management problem.

Consider a general transportation problem as follows

Min $\mathrm{Z}=\sum_{\mathrm{i}=1}^{\mathrm{m}} \sum_{\mathrm{j}=1}^{\mathrm{n}} \mathrm{c}_{\mathrm{ij}} \mathrm{x}_{\mathrm{ij}}$

Subject to $\sum_{\mathrm{j}=1}^{\mathrm{n}} \mathrm{x}_{\mathrm{ij}} \leq \mathrm{S}_{\mathrm{i}}, \mathrm{i}=1,2, \ldots \mathrm{m}$

$$
\sum_{\mathrm{i}=1}^{\mathrm{m}} \mathrm{x}_{\mathrm{ij}} \geq \mathrm{d}_{j}, \mathrm{j}=1,2, \ldots . \mathrm{n}
$$


Where $\mathrm{x}_{\mathrm{ij}} \geq 0, \forall(\mathrm{i}, \mathrm{j})$

The objective function minimizes the total cost of transportation between various sources and destinations. The constraint $i$ in the first set of constraints ensures that the total units transported from the source $\mathrm{i}$ is less than or equal to its supply. The constraint $\mathrm{j}$ in the second set of constraints ensures that the total units transported to the destination $d_{k}$ is less than or equal to its demand.

This transportation problem is unbalanced if either of the following happens.

$$
\begin{array}{ll}
\text { i. } & \sum_{\mathrm{i}=1}^{\mathrm{m}} \mathrm{S}_{\mathrm{i}}>\sum_{\mathrm{j}=1}^{\mathrm{n}} \mathrm{d}_{\mathrm{j}} \\
\text { ii. } & \sum_{\mathrm{i}=1}^{\mathrm{m}} \mathrm{S}_{\mathrm{i}}<\sum_{\mathrm{j}=1}^{\mathrm{n}} \mathrm{d}_{\mathrm{j}}
\end{array}
$$

This scenario depicts an economic situation which is frequently encountered in practice when demand is more than the availability or supply. The researcher observes that capacity of the two dump sites in the study area is greater than the waste generated from the sours ( kebeles').

To be the general transportation problem is feasible, $\sum_{\mathrm{j}=1}^{\mathrm{n}} \mathrm{d}_{\mathrm{j}} \leq \sum_{\mathrm{i}=1}^{\mathrm{m}} \sum_{\mathrm{j}=1}^{\mathrm{n}} \mathrm{x}_{\mathrm{ij}} \leq \sum_{\mathrm{i}=1}^{\mathrm{m}} \mathrm{S}_{\mathrm{i}}$.

Knowing that the total demand of the destinations cannot be fully met, we can talk only about the best compromise solution of (GTP). When $\sum_{j=1}^{n} d_{j}>\sum_{i=1}^{m} S_{i}$ it is necessary specify priorities of destinations in other words of we say that destination $d_{j}$ is of more importance than $d_{k}$ then it actually means that the demand $b_{j}$ of $d_{j}$ must get fulfill even if we have to sacrifice with the demand $b_{k}$ of $d_{k}$. Mathematically this can be achieved by associating penalties $p_{j}$ with the destinations $d_{j}$. Finally we introduce an additional (dummy) source $\mathrm{S}_{\mathrm{m}+1}$ with the assumption, that at this source we can procure $\mathrm{S}_{\mathrm{m}+1}$ unites of the commodity, where, $S_{m+1}=\sum_{j=1}^{n} d_{j}-\sum_{i=1}^{m} S_{i}>0$. Then we set $c_{m+1 j}=p_{j}, j=1,2, \ldots, n$, where $p_{j}>0$ is the penalty for not fulfilling the requirements of $d_{j}$. After unbalanced transportation problem changed to balanced transportation problem there are two phases in transportation problem.

\section{Phase I: Finding initial Basic Feasible Solution}

Any solution $\mathrm{X}_{\mathrm{ij}} \geq 0$ is said to be a feasible solution of a transportation problem if it satisfies the constraints. The feasible solution is said to be basic feasible solution if the number of non-negative allocations is equal to $(m+n-1)$ while satisfying all rim requirements, i.e., it must satisfy requirement and availability constraint. There are three methods for solving TP (North West Corner, Minimum Cost method or Matrix Minima Method and Vogel's Approximation Method) used to get basic feasible solution.

\section{Phase II: Finding optimal Solution}

While modified distributed (MODI) and Stepping Stone method are considered as a standard technique for obtaining to optimal solution [8]. A feasible solution of transportation problem is said to be optimal if it minimizes the total cost of transportation. There always exists an optimal solution to a balanced transportation problem. We start with initial basic feasible solution to reach optimal solution which is obtained from above three methods. We then check whether the number of allocated cells is exactly equal to $(m+n-1)$, where $m$ and $n$ are number of rows and columns respectively. It works on the assumption that if the initial basic feasible solution is not basic, then there exists a loop.

\section{Assumptions}

1. All generated solid waste in Jimma town is collected and transferred to disposal area.

2. Collection of waste is done, when there is no traffic jam.

3. Every ward (kebele) is considered as a generation node.

\section{Network Representation and Mathematical Model of Transportation Problem}

The transportation model is represented by network in Figure1 bellow. There are $m+1$ sources and $n$ destinations, each represented by anode. The arcs represent the routes linking the sources and destinations'. Arc (i,j) joining source $i$ to destination $j$ carries two pieces of information: the transportation cost per unit, sign and the amount shipped, $\mathrm{x}_{\mathrm{ij}}$. The amount of supply at source $i$ is $S_{i}$, and the amount of demand at destination $j$ is $d_{j}$. the objective of the model is to determine the unknowns' $x_{i j}$ that will minimize the total transportation cost while satisfying the supply and demand restrictions. 


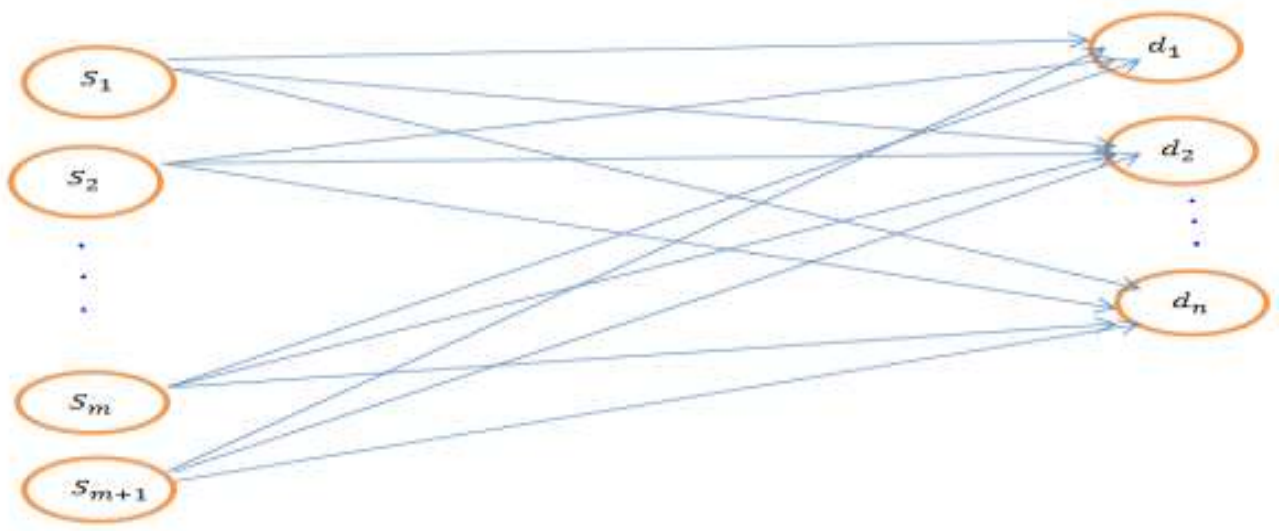

Figure 1: Network representation of transportation problem.

The transportation problem is unbalanced (demand $>$ supply), hence to convert unbalanced transportation problem to balanced transportation problem dummy source $S_{m+1}$ was added as a generation nod of the model and the general balanced transportation matrix is as follows.

Table2: The transportation matrix.

\begin{tabular}{|c|c|c|c|c|c|c|c|c|}
\hline \multirow{3}{*}{$\begin{array}{l}\text { Source (i) } \\
1\end{array}$} & \multicolumn{7}{|c|}{ Destination (j) } & \multirow{3}{*}{$\begin{array}{c}\text { Supply }\left(S_{i}\right) \\
S_{1}\end{array}$} \\
\hline & \multicolumn{2}{|l|}{1} & \multicolumn{2}{|l|}{2} & $\ldots$ & \multicolumn{2}{|l|}{$\mathrm{N}$} & \\
\hline & $\mathrm{x}_{11}$ & $\mathrm{c}_{11}$ & $\mathrm{x}_{12}$ & $\mathrm{c}_{12}$ & $\ldots$ & $\mathrm{x}_{1 \mathrm{n}}$ & $\mathrm{c}_{1 \mathrm{n}}$ & \\
\hline 2 & $x_{21}$ & $c_{21}$ & $x_{22}$ & $c_{22}$ & $\cdots$ & $x_{2 n}$ & $c_{2 n}$ & $\mathrm{~S}_{2}$ \\
\hline$\ldots$ & $\ldots$ & & $\ldots$ & & $\ldots$ & & & $\ldots$ \\
\hline M & $\mathrm{x}_{\mathrm{m} 1}$ & $\mathrm{c}_{\mathrm{m} 1}$ & $\mathrm{x}_{\mathrm{m} 2}$ & $\mathrm{c}_{\mathrm{m} 2}$ & $\ldots$ & $\mathrm{x}_{\mathrm{mn}}$ & $\mathrm{c}_{\mathrm{mn}}$ & $\mathrm{S}_{\mathrm{m}}$ \\
\hline$m+1$ & $x_{m+11}$ & $c_{m+11}$ & $x_{m+12}$ & $c_{m+12}$ & $\cdots$ & $x_{m+1 n}$ & $c_{m+1 n}$ & $\mathrm{~S}_{\mathrm{m}+1}$ \\
\hline Demand (dj) & & & & & $\ldots$ & & & \\
\hline
\end{tabular}

Using general transportation matrix the amount of waste from the source, the capacity of the two disposal sites and the distance between each kebeles to the tow disposal sites were analyzed using vogles approximation and we have the following results.

\section{COMPUTATIONAL RESULTS}

The major problem of jimma municipality waste management is transportation. Jimma municipality transported the collected waste to both disposal sites without considering the distance and the capacity of the dump sites.

This work applies operational research to reduce transportation cost. The existing scenario for transportation of solid waste in Jimma is transporting the waste from each kebele to both the existing disposal sites. Due to that the transport cost becoming very high but we applied a transportation problem for better transportation method. This results much amount of cost reduction than existence one. The results shows that, all wastage generated in Bosa Kito, Bosa Adis, Hermata mentina, Heremata Awetu, Ginjo Guderu, Mentina, Heremata Merekato, Furestalie and Effa Bula kebeles will be transported to Seka (koshi) disposal site. Additionally from Mendera Koch Kebele 29 tone waste will transfer to Seka disposal site. Whereas all wastage generated in Jiren, Bacho Bore, Ginjo, ginjo guderu kebeles and 237 ton waste from Mendera Kochi kebele will be transferred to Marawa disposal sit 
International Journal of Scientific and Academic Research (IJSAR), Vol.1, Issue 10, December-2021

Table 3: Basic feasible solution of the transportation problem

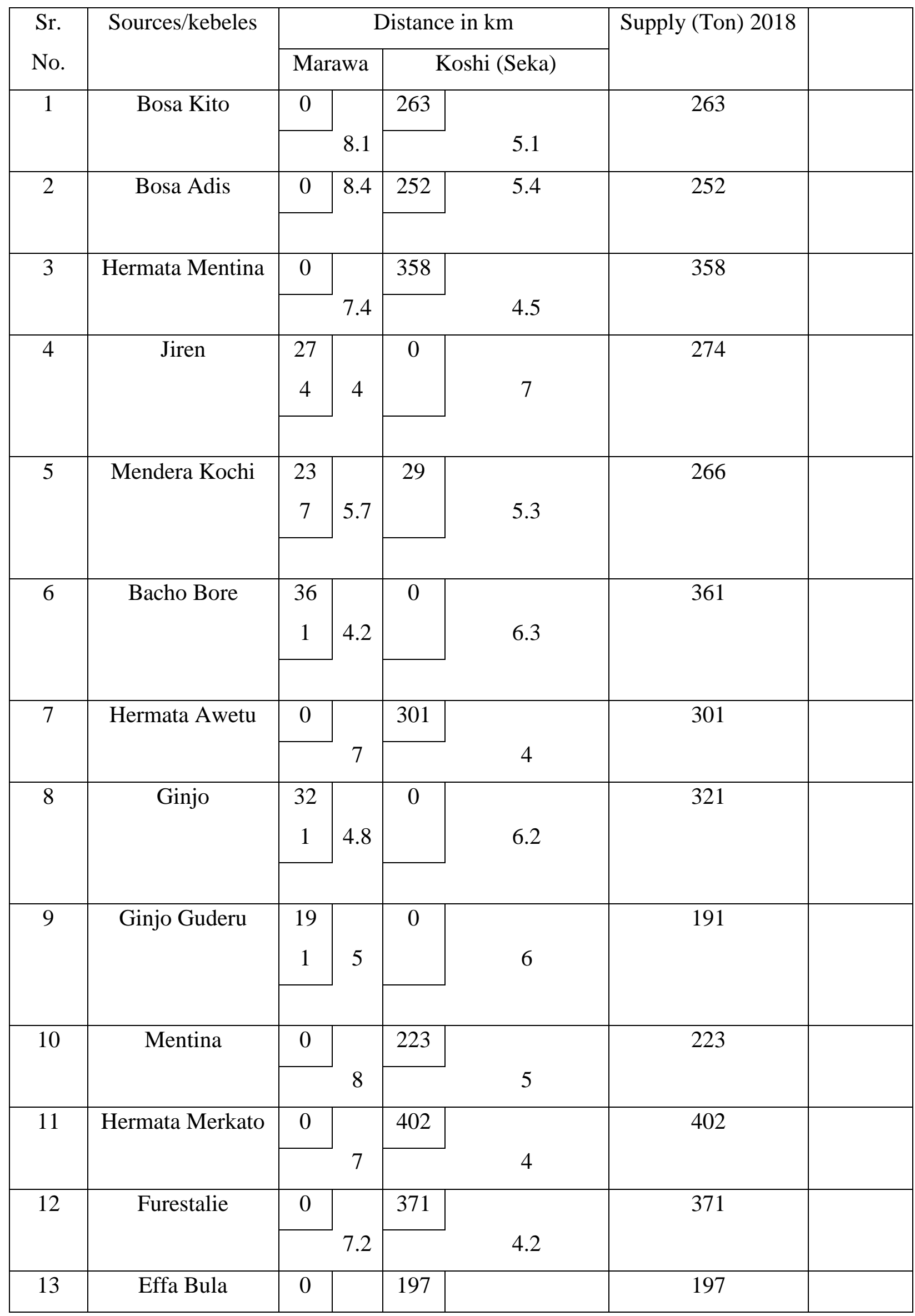


International Journal of Scientific and Academic Research (IJSAR), Vol.1, Issue 10, December-2021

\begin{tabular}{|l|c|c|c|c|c|c|c|}
\hline & & \multicolumn{2}{|r|}{7.6} & \multicolumn{2}{|l|}{4.7} & & \\
\hline 14 & Dummy & 38 & & 0 & & 380 & \\
& & 0 & 0 & & 0 & & \\
\cline { 4 - 8 } & & & & & & \\
\cline { 3 - 7 } & & & & & & & \\
\hline
\end{tabular}

The basic feasible solution of the transportation problem was presented in table 3 , but to show the optimality of the basic feasible solution the value of $u_{i}$ and $v_{j}$ for allocated cells and the penalty cost of none allocated cells using $U-V$ method $\left(u_{i}+v_{j}=c_{i j}\right.$ and $P_{i j}=u_{i}+v_{j}-c_{i j}$ ) were presented as follows.

Table 4: The penalty cost of Jimma town waste transportation problem

\begin{tabular}{|c|l|l|l|l|l|l|}
\hline & \multicolumn{2}{|l|}{ Marawa } & \multicolumn{2}{l|}{ Seka/koshi } & & \\
\hline$u_{i}$ & Allocation & Distance & Allocation & Distance & Supply & \\
\hline$u_{1}=0$ & 0 & 8.1 & 263 & 5.1 & 263 & -2.6 \\
\hline$u_{2}=0.3$ & 0 & 8.4 & 252 & 5.4 & 252 & -2.6 \\
\hline$u_{3}=-0.6$ & 0 & 7.4 & 358 & 4.5 & 358 & -2.5 \\
\hline$u_{4}=-1.5$ & 274 & 4 & 0 & 7 & 274 & -3.4 \\
\hline$u_{5}=0.2$ & 237 & 5.7 & 29 & 5.5 & 266 & \\
\hline$u_{6}=-1.3$ & 361 & 4.2 & 0 & 6.3 & 361 & -2.5 \\
\hline$u_{7}=1.1$ & 0 & 7 & 301 & 4 & 301 & -2.6 \\
\hline$u_{8}=-0.7$ & 321 & 4.8 & 0 & 6.2 & 321 & -1.8 \\
\hline$u_{9}=-0.5$ & 191 & 5 & 0 & 6 & 191 & -1.4 \\
\hline$u_{10}=-0.1$ & 0 & 8 & 223 & 5 & 223 & -2.6 \\
\hline$u_{11}=-1.1$ & 0 & 7 & 402 & 4 & 402 & -2.6 \\
\hline$u_{12}=-0.9$ & 0 & 7.2 & 371 & 4.2 & 371 & -2.6 \\
\hline$u_{13}=-0.4$ & 0 & 0 & 197 & 4.7 & 197 & -2.5 \\
\hline$u_{14}=-5.5$ & 380 & 0 & 0 & & 0 \\
\hline
\end{tabular}

As we see table 4 all values of $p_{i j} \geq 0$, this indicates that the solution of the transportation problem is basic feasible and optimal solution .

Generally, results shows that $36.61 \%$ of generated waste flow should be routed to the Marawa and the remaining $63.39 \%$ should be to Seka/ Koshi disposal areas. 


\section{CONCLUSION AND RECOMMENDATION}

\subsection{Conclusions}

Waste management in Jimma, is one of the largest challenges that public administrators face because of the increasing quantities of different material streams and consumable products which become more and more complex. It is extremely recognized that the existing solid waste management practice in Jimma town is ineffective both in terms of collection, transportation and sanitary treatment of the waste. Due to luck of budget even the collected waste is not transported to the waste disposal site early. To reduce transportation cost there is a need to apply operational research on solid waste transportation system. The main purpose of this work is giving effective transportation system of solid waste by obtaining optimal basic feasible solution of the transportation problem.

In this paper, motivated by a real case scenario of a waste collection problem, we proposed unbalanced transportation problem with two waste disposal sites and thirteen generation nodes /kebeles. The formulated problem was then solved by Vogles approximation method and the optimality of the basic feasible solution was tested by U-V method. This study tells which generation nod at which disposal area should be transported.

\subsection{Recommendations}

* Municipalities should know which generation nod at which disposal area should be transported.

* Waste management system in the study area is the duty of jimma town municipality office but the magnitude of the problem is beyond the ability. They need the help of other governmental and none governmental bodies in addition to the general community need to be more involved starting from waste collection up to disposal.

* To overcome shortage of budget the municipality should convert the waste itself as a source of income by characterized the type of waste as recyclables, combustible, non-combustible.

* The municipality should give legal responsibility for institutions, commercial, factories and large hotels (produced much amount of waste) in order to transport their own wastes to the waste disposal area.

* Solid waste reduction at the source is the preferable and crucial means to management system. This will be done by mobilizing the community to participate in solid waste collection, transportation and disposing.

* The collected waste wait many days /weeks or months in the containers this cause health problems, so the town administration should give attention to transport the waste early.

\section{Acknowledgements}

Foremost and above all I would like to thank the Almighty GOD for giving me the strength and wisdom to successfully complete this work. Last but not least I would like to extend my best and heartfelt thanks to my wife Instructor Kedist Meshesha Ejigu for her moral, spiritual and all-round support.

\section{Data Availability Statement}

All data generated, analyzed and used during this study are included

\section{Competing interests}

The authors declare that they have no competing interests.

\section{REFERENCE}

[1] Hayal D., H. W. (2014). Assessment of the Contemporary Municipal Solid Waste Management in Urban Environment :The case of Addis Ababa Ethiopia. . Enviromental science and technology.

[2] UNEP. (2005). Selection, Design and Implementation of Economic Instruments in the Solid Waste Management Sector in Kenya. Nairobi Kenya. United Nations Environment Programme.

[3] Mengistu H., Assegid A. (2014). Solide waste management in Adama, Ethiopia aspects and challenges. world academy of science, Engineering and techenology. 
[4] Yohannis Fetene. (2018). Client satisfaction to wards municipal solid wast msnagement service in Jimma city, south waste Ethiopia. international journal of environmental science and natural resource.

[5] Dereje T., M. (2017). Assesing potential and characterization of solid waste of Jimma town. Imperial journal of interdisciplinary research(IJI).

[6] Naol S. (2018). Determinantes of effective household solid waste management practices in Jimma town, Ethiopia. International journal of advanced research (IJAR).

[7] Balaban, O. (2012). The negative effects of construction boom on urban planning and environment in Turkey. Haitat International.

[8] KN Chinchodkar and Omprakash. (2017). Development of Mathematical Model for the Solid Waste Management on Dumping Ground at Mumbai for the Reduction of Existence Cost. International journal of Statistics and systemes.

[9] World Bank. (2012). Annual report on Environmental Protection . Washington.DC: World Bank. 